\title{
Comparing communities of inquiry of Portuguese higher education students: One for all or one for each?
}

\author{
José António Moreira \\ Department of Education and Distance Teaching, Universidade Aberta (Open University), \\ (Portugal) \\ António Gomes Ferreira \& Ana Cristina Almeida \\ Faculty of Psychology and Educational Sciences, University of Coimbra (Portugal)
}

\begin{abstract}
The purpose of this study was to report evidence obtained in a survey based on the Community of Inquiry (Col) framework (Garrison, Anderson \& Archer, 1991; 2000) carried out in different groups. The study comprised 510 higher education students enrolled in blended online courses offered through Moodle platform during one semester. It considered students from different private and public Portuguese polytechnic schools and universities. Moreira \& Almeida (2011) have suggested that Col framework is a valid, reliable, and efficient measure of its dimensions within the Portuguese population. Although similarities in aspects of social presence were discovered among polytechnic and universities students, the two groups showed some differences. In particular, it was observed that the polytechnic students appear to be a more robust community when compared to university students.
\end{abstract}

Keywords: Blended Learning; Community of Inquiry; Learning Community; Online Learning; Polytechnic; University

\section{Introduction}

Today, the large number of students per class and the traditional methods of teaching are hardly compatible with one of the most fundamental requirements of higher education-skills training. This indicates that the current teaching methods and the role of both teachers and students must be reorganized. Students are expected to acquire knowledge, gain practice and develop their competences. More and more the use of technological tools to support teachers begins to flourish as a source of continued cognitive, social and dialogical presence in the learning process. Teachers may guide the instructional process by being present and coping with the pedagogical relationship in a blended web-based learning. However, such helpful resources must convey a paradigm establishing the relationship relational climate to an effective educational experience. So, the need for a community is imperious, specifically one of inquiry, in order to promote skills and knowledge in a constructivist and collaborative environment suitable for the work of professionals, who are expected to be autonomous, active and effective in performing their functions (Garrison, Anderson, \& Archer, 2000).

The Col framework is a process model that provides a comprehensive theoretical frame able to support both online learning research and the practice of online instruction. It assumes that effective online learning requires the development of a community (Shea, 2006, cf. Swan et al., 2008; Thompson \& MacDonald, 2005) that supports meaningful inquiry and deep learning. The relevance thereof is based on the fact that young people today that will assume in the future important roles in the political, social and cultural life of the world community. 
In this context, the study we have developed aims to understand the workability of the Col model, while examining its impact on the creation of blended learning online communities. To this end, we aim to explore possible relationships between face-to-face instruction, fostering a valuable pedagogical relationship providing key elements central to a collaborative learning environment, and an online teaching model enabling the creation of learning communities.

\section{For an effective cooperative, cognitive and self-regulated learning}

Self-regulated learning is an unquestionable vehicle for fruitful individual progress and global sustainability. Different authors and perspectives characterize self-regulated learning differently: (a) focused on an individual as a regulator of a behavior and referring to the process of becoming a strategic learner by regulating their cognition, motivation and behavior to optimize learning (Schunk \& Zimmerman, 1994); (b) as co-regulation influenced by socio-cultural theory and emphasizing gradual appropriation of sharing common problems and tasks through interpersonal interaction (McCaslin \& Hickey, 2001, cf. Järvelä et al., 2007); or (c) as a process of shared cognition and collaborative learning for the co-construction of shared understanding (Roschelle \& Teasley, 1995).

Similarly to Järvelä, Näykki, Laru and Luokkanen (2007), our view assumes collective regulation through shared awareness of goals and solving tasks in networking.

Education is crucial to individual and social development, especially at the higher level of schooling, where the cultural environment can better fertilize the preparation of agents with greater social responsibility. In addition to the emerging changes, we will need to master specific contents, a solid knowledge base, and hard study in order to meet quality standards, be committed to social development and to be an expert in decision-making.

The tendency is to value student-centered education, use resources to provide guidance to teaching, ask each student to work at their own pace, to have open systems without formal parameters, provide curricula focused on the end-goals of students, provide a selected offer to optimize relevance, work and performance-based learning contexts, networked environments, interactive teaching, global perspectives and anticipatory educational management (Ally, 2004). This means innovating instead of resisting change in order to make Higher Education institutions more proactive and, even more importantly, to emphasize the role and responsibilities of the student community in this effort.

Despite the undeniable existence of austere educational systems centered in subject teaching and in the master role of teachers as transmitters of a theoretical and static academic culture, there have been various experiences all over the world to encourage classroom participation, cognitive enhancement and address the well-being of civil society. Some of these experiments stimulate the use of technology tools to regulate collaborative learning, like wireless networks and mobile tools, laptops, multimedia note taking, computing tools, messaging or chat (e.g., Järvelä et al., 2007).

By defending difficult initiatives to integrate innovative pedagogical ideas with the desired cognitive load and technological support, we address a scaffolding teaching model during the dynamic process of online-based instruction.

The Community Inquiry framework (Arbaugh et al., 2008; Garrison \& Anderson, 2003; Swan et al., 2008) is considered one of the most promising schemes for modeling online teaching. As a broad and integrated model, it explains successful teaching, allowing the research and monitoring of learning processes in a collaborative, interactive and constructivist approach. The underlying idea of the model is that an educational Community of Inquiry is a group of individuals who collaboratively engage in purposeful critical discourse and reflection to construct personal meaning and confirm 
mutual understanding (Garrison \& Anderson, 2003). In this sense, successful learning stems from three critical elements that interact with each other and are mutually influenced: the cognitive presence, the social presence and the presence of teaching. Taking into account the vast literature on these elements (e.g., Swan et al., 2008), our aim is to test our own educational experience. In other words, as we have mentioned before, we want to verify if our teaching process has a structure and organization that encourages a diversity of perspectives, promoting research, criticism and creativity in a collaborative learning environment.

We wish to enable communities of inquiry, prepare our students to be responsible and to look for the meaning of their own educational experience, through self-regulation and negotiation with the community.

\section{Communities of inquiry in Portuguese education: looking for a triangulation in the instruction-learning process}

Overall, there is a general claim that new technologies and software used in education should offer new learning opportunities allowing for a third element to consolidate those contents, turning them into effective learning experiences. This third pole would be the communities of inquiry. Motivation can, however, also be driven by technology into learning extracurricular subjects and being responsive to instructional intervention.

So far, some case studies and design experiments were carried out, for instance, on mobile technologies used for innovative pedagogical ideas and instructional design. However, only a few studies have given detailed arguments as to what these new opportunities are in terms of learning interaction and collaboration, and the exact processes that mobile tools can support. We believe that what matters and sustains the argument in applying the most modern tools for education is that students increase their opportunities to interact and share ideas, thus increasing the opportunities for an active mind in multiple contexts (cf. Järvelä, Volet \& Järvenoja, 2010). So, potentially, networks and technological tools can support collaborative learning in higher education. Nonetheless, we are not familiar with this situation in our learning contexts. Therefore, we ought to approach innovation by linking some methodological introductions to the most usual ones, in an attempt to gradually introduce changes that can raise the learning patterns. The emergence of assumed and identified communities of inquiry between teacher and students are an important facilitator in this process.

We infer that the Col model, in its three presences, contributes to the construction of a learning community, potentially able to provide formative and summative feedback about the effectiveness of courses or programs with an online component.

Indeed, the Col theoretical framework represents a process of creating deep and meaningful learning through collaborative and constructivist experiences. This is achieved by developing the three interdependent elements, although cognitive growth depends strongly on social interaction and discourse to share views and exchange information. Subsequent work could explore the role of metacognition within the framework, by operationalizing the construct in its metacomponents in learning processes management, including self-regulation and the monitoring and evaluation of processing modeled by affective experience and dialogical support (Hmelo-Silver, 2003).

The learning community of inquiry needs to highlight conceptual differences between the presences in online learning contexts, as well as the dynamics between them. The identification of the processing elements that facilitate, or hinder, higher learning and the ability to solve complex learning problems has implications for the teaching practice, too. Using either the Col model or other methodological and instrumental resources, ongoing research is needed, both in a qualitative 
and a quantitative approach, as other studies have done towards consistently defining communities of learning (Hmelo-Silver, 2003),

\section{Context of study}

Based on the assumptions of the theoretical model and on previous exploratory work on the Col framework (cf. Garrison \& Col.), we expect the three presences—cognitive, social and teaching-will appear distinctly, yet overlapping or related to each other for all the groups of students surveyed.

The participants in this study are undergraduate students $(n=510)$ enrolled during the school year of 2010/2011 in blended online courses offered through Moodle platform during one semester at different Portuguese schools (polytechnic private institutes and public universities). The study involved students of a Higher School of Education, a Higher School of Health and a Faculty of Psychology and Educational Sciences of a classic University.

In Portugal, both the universities and higher schools provide higher education. But while the main goal of polytechnic institutes is professional training and gaining practice and knowledge, universities are still oriented to the creation, transmission and dissemination of high patterns of culture, science, literature and technology through study and research in the various content areas of knowledge. Thus, in universities, especially in the classic ones, the curricula include an overload of information and cognitive workload, so that the greater demands of teaching foster receptive learning and formality, and tend to encourage higher job isolation and academic scientific preparation of students in a more traditional mode.

Based mainly on the principles of interaction and collaborative and independent learning, we sought to develop a model taking as reference the view of Garrison, Anderson and Archer (2000) based on the development of skills and student-centred learning. These were the principles that guided the organisation of education, the shaping of student and teachers' roles, the planning, design and management of learning activities, the definition of the types of materials to be developed and the nature of the assessment of skills acquired.

The student therefore lies at the centre of this pedagogical model and is an active element, building his/her knowledge, committed and engaged in the learning process and integrated in a community of learning. Overcoming the methods and educational tasks, the different teaching situations present in this model are designed according to the student and to a learning process intended to facilitate the acquisition of skills required for living in a knowledge society, and specific skills related to the area chosen by the student.

According to this model, learning is achieved through collaborative learning strategies and is the result of joint work, shared knowledge and prospects, based on common goals and work methods agreed within the group. The aim of creating and organizing student groups is to reach the conclusion that the construction of knowledge must be socially contextualized (Garrison \& Anderson, 2003).

This model also defined a new role for the teacher, to the extent that more than being a source of information, the teacher becomes a guide, a facilitator of learning who encourages students to interact in the learning community (Moreira \& Monteiro, 2010).

Another principle of the model is based on the rule of interaction. In the first generations of distance learning, interaction was essentially seen as student-content interaction and studentteacher interaction. Moreover, this model extends those dynamics into a student-student interaction by creating discussion groups within each class and each virtual classroom. This means that they have to be planned in advance, and learning strategies need to be activated in order to stimulate initiative, involve students, ensure that they are committed and guide the nature of their work. 
In this model, interactions are shaped as the practical basis of learning and are based on constructivist and socio-interactionist theories, as they require the negotiation of conflicts and sharing of meanings (Monteiro, 2011).

\section{Methodological aspects}

The Community of Inquiry framework has been presented as a valid and reliable instrument to measure the quality of online teaching focusing on the three important components (Klenner-Moore, 2002; Vaughan \& Garrison, 2005). In that sense, although classes are large and have different course programmes, we sought to study the contribution of the model in testing the settings we have defined to promote meaningful collaborative learning. Our goal is to compare Col measures to illustrate the three presences as our students feel them, in each targeted community and in all three as a whole.

\section{Participants}

The sample was formed by 510 undergraduate students: 338 (66.3\%) female and $172(33.7 \%)$ male students enrolled in public and private higher schools (polytechnic institutes) and universities, taking blended online courses offered through Moodle platform during one semester of the 2010/2011 school year. This study involved Portuguese Health, Education and Psychology students. The group included 150 (29.4\%) Psychology students, 182 (35.7\%) Health students and 178 (34.9\%) Education students. $150(29.4 \%)$ of those students attended public universities, $162(31.8 \%)$ private universities and $198(38.8 \%)$ private higher schools of polytechnic institutes. Their age varies between 17 and 60 years, but mostly is between 17 and 34 years old (59.8\% of the respondents are in the $17-24$ age group, and $24.8 \%$ in the $25-34$ age group).

\section{Instrument}

The instrument used to study the learning community in all three teaching environments was the Community of Inquiry Survey of Garrison et al., properly translated and adapted. Like the original, the survey instrument contains a random sequence of 34 items of the ten categories of factors that combine the three elements required in any desirable learning context, as they are distributed in the coding template (Table 1, cf. Garrison \& Anderson, 2003). Students were asked to indicate their degree of agreement with each item (from Strongly Disagree to Strongly Agree) on a five-point Likert scale.

The 34-item instrument was implemented in three institutions in the school year of 2010-2011, with singularities (e.g., public vs. private school institution) and common features such as the lecturing of identical courses. The sample criterion was to recruit students of online tutoring teachers on the Moodle platform.

\section{Resulting communities}

\section{What the Col survey reveals about the existing communities of inquiry}

Each student answered the survey questionnaire at the end of the course. During the course, each teacher created his/her own dynamics, fostering knowledge and pedagogical relationships through web mediation, particularly through the creation of virtual classrooms in the online environment. The aim of the dynamics was to favor work attitudes and collaborative learning. Group activities were set in place to enhance this collaborative work, with classrooms assigned to each group so 
Table 1: Community of Inquiry Coding Template

\begin{tabular}{|l|l|l|}
\hline Elements & CATEGORIES & INDICATORS (examples) \\
\hline \multirow{4}{*}{$\begin{array}{l}\text { COGNITIVE } \\
\text { PRESENCE }\end{array}$} & Triggering Event & Sense of puzzlement \\
\cline { 2 - 3 } & Exploration & Information Exchange \\
\cline { 2 - 3 } & Integration & Connecting ideas \\
\cline { 2 - 3 } & Resolution & Apply new ideas \\
\hline \multirow{3}{*}{$\begin{array}{l}\text { SOCIAL } \\
\text { PRESENCE }\end{array}$} & Affective Expression & Emotions \\
\cline { 2 - 3 } & Open Communication & Risk-free expression \\
\cline { 2 - 3 } & Group Cohesion & Encouraging collaboration \\
\hline \multirow{3}{*}{$\begin{array}{l}\text { TEACHING } \\
\text { PRENCE }\end{array}$} & Design \& Organization & Defining/initiating discussion topics \\
\cline { 2 - 3 } & Facilitation & Sharing personal meaning \\
\cline { 2 - 3 } & Direct Instruction & Focusing discussion \\
\hline
\end{tabular}

that members could communicate among each other and with the other groups. The idea was to have students avoid conceptual isolation attitudes and adopt reflexive and critical attitudes, sharing discussions, debates, systematic arguments and counter-arguments, thereby encouraging "one for all" attitudes rather than "every man for himself."

Ordinal responses were scored using a 1-5 point-scale (from Strongly Disagree to Strongly Agree). After statistic data was processed, we saw that mean responses for all the 34 items ranged from 3.74 to 4.24 , with a global median of 3.98 and a variance of 0.016 . Standard deviation ranged from 0.66 to 0.89 .

The Shapiro-Wilk test of normality showed that none of the analyzed variables presented a normal distribution along the 34 items, all of them showing a negative skewness. Looking at the descriptive statistics, we can situate the central measures around point 4 , which reveals that, in general, students agreed that they belong to a community of inquiry in all the indicators considered.

The non-parametric Kruskall-Wallis test was used to understand if the three groups, taking into consideration their different fields of study, differed about the way they perceived themselves in the process and learning environment. Through a "variance" analysis by ranks, we found the aggregate degree to which the groups differ. The Psychology students' group was the highest, ranking only in 5 items that have in common a social dimension of learning in the community (e.g., "I was able to form distinct impressions of some course participants," "I used a variety of information sources to explore problems posed in this course," "I felt comfortable interacting with other course participants," "I felt that my point of view was acknowledged by other course participants," "The instructor encouraged course participants to explore new concepts in this course").

The group formed by health students highlighted their sense of participation in the inquiry community in other 5 items. All of them dealt with instruction supported by communication: ("I felt comfortable conversing through the online medium," "Brainstorming and finding relevant information helped me solve content-related questions," "The instructor clearly communicated important course topics," ". . . clearly communicated important course goals," ". . provided feedback in a timely fashion"). 
In all the other items, the group of education students scored the highest, differing significantly in measures assembling most of the items. Since they are studying to become teachers, we may speculate that perhaps they are more aware of the importance of a learning community. At the same time, they are learning to be teachers following a model (White \& Frederiksen, 1998) to implement and guide the teaching procedures with an online component.

We also used non-parametric tests to study how variables of the theoretical model of learning communities intended for the online medium behave in terms of cognitive, teaching and social presences, and their frequency. We hoped to infer the probability of a particular event taking place again. In that sense, online teaching allows the students to better learn, equate and discuss subject matters in order to build their academic pathway.

After checking that all the 34 items were highly and significantly correlated, conditions were in place to produce a model so that the various items share common factors.

The Kaiser-Meyer-Olkin Measure of Sampling Adequacy test with KMO $=0.968$ indicates that the variables are apt to enter the model. Moreover, Bartlett's sphericity tests the hypothesis that the correlation matrix is not the identity matrix $\left(x^{2}=10758,380\right.$, df $\left.561, p<0.001\right)$.

\section{Factor analysis and internal consistency}

As a whole, these tests provide a minimum standard that should be addressed before carrying out a principal components analysis (or a factor analysis). Principal components analysis is a method of data reduction, aiming to reduce the 34 measures to a few principal components. The purpose of the exploratory factor analysis was to assess the underlying structure of the Col instrument used to measure the three elements after an online learning experience.

There were four factors with Eigen values greater than one. The exploration of the underlying structure of the variables that rotate the four factor solutions obtained revealed the interpretability of a simple structure, evidenced by the intertwining of the factors. Therefore, looking for the best correspondence to the theoretical model, we chose a three-factor oblimin solution. We expect it to be the best solution since the three factors of the community of inquiry are seen to be overlapping. Neither the cognitive nor the social or the teaching elements could exist without the others in an accurate experience of learning, even if it is partial online learning. So, taking into account the assumptions of the theoretical model and previous exploratory work, we used principal component analysis with oblimin rotation to confirm the three elements. We expect they will be distinct yet overlapping. The analysis of the scree plot (Figure 1) supports the three factor construct predicted by Col's theoretical basis and previous exploratory research. Specifically, the marked decrease in magnitude of the factors did not support a framework by a larger than anticipated number of factors.

The three components extracted accounted for $55.6 \%$ of the total variance.

Table 2 illustrates the $34 \mathrm{Col}$ items factor loadings, with the three factors highlighted for interpretability.

Hence, we can see that the relevance of principal components analysis is to redistribute the variance in the correlation matrix (using the method of Eigen value decomposition) in order to redistribute the variance to the first components extracted.

These results reflect the Pattern Matrix generated by the previously described principal component analysis. In support of this analysis, loadings for the Structure Matrix differed slightly, however both output matrices support the 3-factor model.

There are 18 items loading most heavily on Factor 1, 9 items loading most heavily on Factor 2, which is consistent with the Teacher Presence and, finally, 4 items loading most heavily on Factor 3. 


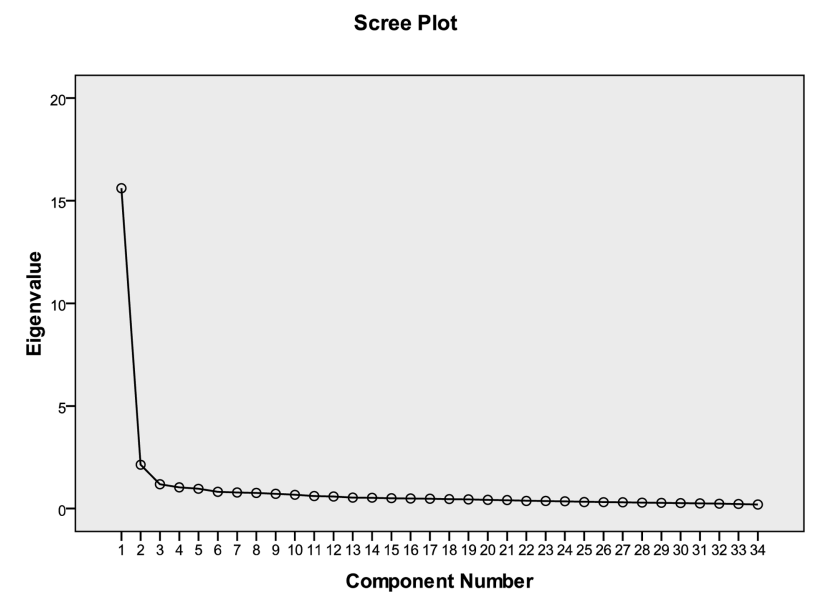

Figure 1: Screen plot principal component analysis of Col survey

The interpretability of these factors in line with the framework and design of the instrument, as to how student perceive the cognitive presence concerning the construction of meaning and understanding subject matters, encompasses the ability of participants to come together for a common purpose. Additionally, the asynchronous virtual community in which students interact may demand a significant teaching presence to manage and monitor the cognitive and social dynamic, and to create a purposeful community of inquiry. This requires recognizing the unique features to achieve educational experiences through the three overlapping areas as the extraction procedures show, producing 8 iterations.

Reliability of the factors (Cronbach's alpha) was high and acceptable, yielding internal consistencies equal to 0.93 for Teaching Presence, 0.91 for Cognitive Presence, and 0.89 for Social Presence (see Table 3).

In addition to the fact that Cronbach's alpha measures high internal consistency for each presence of a set of items, enforcing substantive arguments that the respective items measure the underlying (or latent) construct, we have checked the unidimensionality for each Presence assumed under the educational purpose of the courses through exploratory factor analysis. We verified that for each Presence only one component was extracted.

For the Cognitive Presence factor, loadings in the component matrix ranged from 0.632 to 0.769 and the Eigen value for the first factor is larger than the Eigen value for the next factor $(6.1 \mathrm{vs}$. 0.91). Additionally, the first factor accounts for $51.3 \%$ of the total variance. This suggests that the scale items are unidimensional.

For the Teaching Presence factor, loadings in the component matrix ranged from 0.677 to 0.796 . The initial Eigen value for the first factor is 7.1 versus 0.91 , accounting for $55.2 \%$ of the total variance.

For the Social Presence, $53.4 \%$ of the total variance was explained by the first component with an Eigen value of 4.8, also greater than the subsequent one, with an initial Eigen value of 0.8. So, Teaching and Social Presences are also unidimensionally scaled.

Since the reliable scale was made up of items measuring autonomous Presences, the next step was to observe the scores in each presence (responsive to the framework) and to compare the students by group, that is, how they assumed the cognitive, social and teaching presence when learning from a web platform resource. 
Table 2: Factor loadings in the pattern matrix

\begin{tabular}{|c|c|c|c|}
\hline & \multicolumn{3}{|c|}{ COMPONENTS } \\
\hline & 1 & 2 & 3 \\
\hline Q31_Social P_Open Comunication & ,823 & & \\
\hline Q19_Social P_Group Coesion &, 797 & ,275 &, 106 \\
\hline Q25_Social P_Affective Expression &, 785 & & \\
\hline Q23_Social P_Open Comunication &, 753 & & \\
\hline Q26_Social P_Open Comunication & ,727 & & \\
\hline Q32_Cognitive P_Resolution & ,673 & & ,156 \\
\hline Q21_Cognitive P_Exploration & ,642 & & \\
\hline Q28_Cognitive $\mathrm{P}$ _Triggering Event & ,628 & &, 119 \\
\hline Q34_Social P_Group Coesion &, 611 &,- 139 &, 117 \\
\hline Q30_Cognitive P_Resolution &, 610 &,- 120 & \\
\hline Q27_Social P_Affective Expression &, 576 &,- 183 & \\
\hline Q18_Cognitive P_Integration &, 558 & &, 152 \\
\hline Q13_Cognitive P_Exploration &, 511 & &, 230 \\
\hline Q17_Cognitive P_Exploration &, 508 & &, 222 \\
\hline Q20_Teacher P_Facilitation & ,498 &,- 224 & \\
\hline Q16_Cognitive P_Integration & ,476 &,- 131 &, 178 \\
\hline Q29_Teacher P_Direct Instruction &, 444 &,- 469 &,- 117 \\
\hline Q12_Cognitive P_Integration & ,436 & & ,369 \\
\hline Q22_Teacher P_Facilitation &, 431 &,- 439 & \\
\hline Q11_Social P_Group cohesion &, 429 & & ,286 \\
\hline Q6_Social P_Affect Expression & 357 & & ,340 \\
\hline Q8_Teacher P_Direct Instruction & &,- 857 & \\
\hline 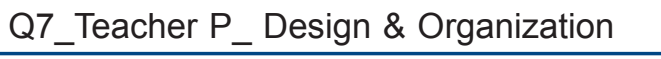 & &,- 827 &, 150 \\
\hline 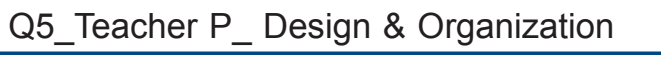 &,- 219 &,- 805 &, 247 \\
\hline Q24_Teacher P_Design \& Organization &, 267 &,- 697 &,- 135 \\
\hline Q15_Teacher $P_{-}$Design \& Organization & &,- 667 &, 120 \\
\hline Q9_Teacher P_Facilitation & , 148 &,- 648 & \\
\hline Q10_Teacher P_Direct Instruction & ,225 &,- 568 & \\
\hline Q33_Teacher P_Facilitation & ,357 &,- 553 & \\
\hline Q14_Teacher P_Facilitation &, 220 &,- 417 & ,202 \\
\hline Q3_Cognitive P_Triggering Event &, 102 & &, 728 \\
\hline Q4_Cognitive P_Triggering Event &, 158 & & ,671 \\
\hline Q1_Cognitive P_Resolution & & & ,650 \\
\hline Q2_Teacher P_Facilitation & ,123 &,- 274 & ,518 \\
\hline
\end{tabular}


Table 3: Reliability coefficients of each factor and of total Col

\begin{tabular}{|l|c|c|}
\hline FACTORS & ALPHA & N. OF ITEMS \\
\hline Cognitive Presence &, 91 & 12 \\
\hline Social Presence &, 89 & 9 \\
\hline Teaching Presence &, 93 & 13 \\
\hline Total Col &, 96 & 34 \\
\hline
\end{tabular}

\section{Descriptive and differential statistic}

Considering the total sample of 510 students, Cognitive Presence items yielded a mean score of 3.92 (s.d. $=0.52$ ), and ranged from 2 to 5 points in the agreement scale. Teaching Presence items yielded a mean score of 4.11 (s.d. $=0.56$ ), with a minimum score of 2 and a maximum score of 5 . Social Presence items collectively yielded a mean score of 3.86 (s.d. $=0.58$ ), ranging from 1 to 5 points.

On average, all the groups of students score Presences near point 4 of the scale, as shown in table 4. This suggests that all the three Presences, both individually and jointly, reveal that students group themselves in communities, in order to perceive themselves as being cognitive and socially present in the learning process.

However, there were differences in the scores obtained that suggest the use of Kruskal-Wallis one-way analysis of variance by ranks. Using this non-parametric method, we tested whether samples of students from different courses and different Higher Education institutions originate from the same distribution. The factual null hypothesis is that the populations from which the samples originate have the same median.

Test statistics K-M taking as grouping variable the institution presents $X^{2}=7.886(p<0.05)$ in respect to the global Col. Taking into account the respective mean ranks, we can read this data as indicating that the public university is a less consistent community of inquiry. Looking for differences among the Presences, we found that they only differ at the Teaching Presence level according to the origin of institutions $\left(X^{2}=10.898, p<0.01\right)$. This result is confirmed after comparing Public vs Private polytechnic institutions using the Mann-Whitney test.

Using the course as the grouping variable in the K-M test, we observed that Psychology students were the lowest ranked ones. They revealed significant differences from the students of the other courses in the global Col $\left(x^{2}=9.22, p=0.01\right)$, in the Teaching Presence $\left(x^{2}=11.176, p<0.01\right)$, in the Cognitive Presence $\left(X^{2}=6.898, p<0.05\right)$, but did not differ from the others in the Social Presence.

Oddly, when we compared students by gender through the Mann-Whitney $U$ test, only in Teaching Presence do the girls exceed their male colleges $(U=25502.500, p<0.05)$, similarly to the Cognitive and Social Presences.

\section{Conclusion}

Considering the axiomatic paradigm of education as a relationship, the proximity between teacher and students and among students, jeopardized by the loss of the status quo of each of the participants in the classroom open to everyone, seems to be recovered by the online learning process. In fact, the results obtained in this study show the relevance of the cognitive presence, the teacher's 
Table 4: Descriptives for each Presence of the Col Survey by group of students

\begin{tabular}{|c|c|c|c|c|}
\hline & & \multicolumn{3}{|c|}{ Course } \\
\hline & & $\begin{array}{c}\text { Psychology } \\
\text { (Public } \\
\text { University) } \\
N=150\end{array}$ & $\begin{array}{c}\text { Health } \\
\text { (Private } \\
\text { Polytechnic) } \\
\mathrm{N}=182\end{array}$ & $\begin{array}{c}\text { Education } \\
\text { (Private } \\
\text { Polytechnic } \\
N=178\end{array}$ \\
\hline \multirow[t]{4}{*}{ Cognitive Presence } & Min & 2 & 2 & 2 \\
\hline & Max & 5 & 5 & 5 \\
\hline & Mean & 3.83 & 3.94 & 4.00 \\
\hline & Std.D & .54 & .52 & .49 \\
\hline \multirow[t]{4}{*}{ Teaching Presence } & Min & 2 & 2 & 2 \\
\hline & Max & 5 & 5 & 5 \\
\hline & Mean & 3.98 & 4.14 & 4.20 \\
\hline & Std.D & .59 & .56 & .53 \\
\hline \multirow[t]{4}{*}{ Social Presence } & Min & 1 & 2 & 2 \\
\hline & Max & 5 & 5 & 5 \\
\hline & Mean & 3.78 & 3.85 & 3.94 \\
\hline & Std.D & .59 & .57 & .58 \\
\hline \multirow[t]{4}{*}{ Global Col } & Min & 2 & 2 & 2 \\
\hline & Max & 5 & 5 & 5 \\
\hline & Mean & 3.87 & 3.99 & 4.06 \\
\hline & Std.D & .53 & .50 & .49 \\
\hline
\end{tabular}

presence and the social presence, and their invaluable potential to mobilize students around the programme core of the instructional proposal in such a modality.

Indeed, regardless of the course and type of institution, we have found that either group is constituted as a community in all indicators. However, although they all perceive a strong social presence when the learning process is guided by web mediation, the study showed that he groups under analysis differ in how they view the cognitive effects and the presence of teaching. In particular, we found that polytechnic students attending health and education courses, in the current context, are positively different when compared to university students attending the psychology courses, which emerge as a less robust online community.

Since we wanted to understand why they differed, we monitored some virtual classrooms using the SNAPP software ${ }^{1}$ and the Netdraw ${ }^{2}$ to analyze the data, we concluded that the differences could be related to how teachers assumed different roles in online discussions. Whereas in the virtual classrooms of polytechnic students the discussions were teacher-centered, in the university student group the discussions were shared by all network members, and the teacher assumed a more peripheral stance. This enabled university students to create small interaction networks between its 
members and to be more autonomous. That is, it appears that the teacher in this group assumed a mediating role, encouraging students to look for information, helping them to reflect on the processes needed to grasp formal concepts. More than imparting knowledge, this teacher sought to guide the learning process by helping students to develop their ability to learn single handedly. While bearing in mind these principles, it seems also the teachers of other groups assumed a more interventive attitude in virtual classroom discussions, controlling the process through dialogue and systematic mediation, which fostered a positive human interaction between the teacher and the learners, not only in terms of cognition but also in terms of emotions.

It is also interesting to note that the results of girls were higher than those of boys in all presences considered, and that their sense of community is significantly superior in the teacher's presence. In order to understand these results, we also monitored some virtual classrooms with the SNAPP software and found that the girls participated more effectively in the discussions, which shows the decisive role they had in the consolidation of social-communicative and social-educational relations that were established in these communities. In this respect, we believe that the variables of socialpsychological circumstances and the emotional aspects, related to their motivation, satisfaction, imagination and creativity, may explain these results.

We can, therefore, conclude that the strategies and methods adopted in the different schools, favoring work attitudes and collaborative learning, in small or large groups, clearly helped develop shared discussion attitudes, arguments and systematic counter-arguments, encouraging attitudes more akin to "one for all" and very distant from the "every man for himself" attitude. So we believe that the answer to the question heading this paper is clear and unequivocal. The expression "one for all" means the strong cohesion established between the different groups of highly participative students, in virtual classrooms.

Based on this data, we can conclude that it is increasingly important to structure balanced relationships between social, cognitive and teaching presences in order to provide significant educational experiences based on a model of collaborative work.

Underlying this work model is a reflexive dialogue that addresses specific items on the personal interests of interacting individuals, as the result of the collective inquiry promoted by the community. In this context, if we accept that virtual environments are innovative tools for creating learning communities, and that psychological tools profoundly influence our view of the world, then it is crucial to recognize the need for a new perspective on the creation of learning contexts and to recognize that the process needs to be supported by collaborative and learning pedagogical models, in that they allow us to link different learning styles (Moreira, 2012).

So, in this sense, each community of inquiry of Portuguese higher education students must be structured focusing specifically on what must be learned and the learning outcomes. Moreover, teachers as tutors must explain how students will learn to learn, directing the instruction to heuristic procedures, including self-assessment, so that students are aware of their sustained and systematic cognitive construction. The opportunities of online learning are of paramount importance to allow for convergence and provide benefits for all, so that the supply of higher education can be an ongoing construction of all for all, safe and with quality.

We need to emphasize that given their limitations these results should be interpreted with caution. Like any other work, ours also has limitations, some of which we recognize immediately, for e.g., external validity, since the results cannot be understood as final and overall applicable. Indeed, note that the empirical component of research is quantitative, resulting from the quasi-experimental plan, because we our study consists of about 500 public and private, polytechnic and university higher education, already placed in classrooms, but not randomly, drawn from what Moore (1983) called experimentally accessible population. 
Our intention is to do justice to the theme, due to its relevance and the impact it deserves in practical terms. In our opinion, this work cannot be seen as completed, but it should rather assume an instrumental nature, useful for those who want to make use of it as a consultation or critique instrument, or even as a starting point for other pragmatically valid work, in order to enrich the range of contributions to understand the issues on the agenda.

\section{Notes}

1 SNAPP-Social Networks Adapting Pedagogical Practice, Retrieved from http://research.uow.edu.au/ learningnetworks/seeing/snapp/index.htm

2 Netdraw (software), Retrieved from http://www.analytictech.com

\section{References}

Ally, M. (2004). Designing Effective Learning Objects. In R. McGreal (Ed.), Online Education Using Learning Objects (pp. 87-97). London \& New York: RoutledgeFalmer.

Arbaugh, J. B., Cleveland-Innes, M., Diaz, S. R., Garrison, D. R., Ice, P., Richardson, J. C., \& Swan, K. P. (2008). Developing a community of inquiry instrument: Testing a measure of the Community of Inquiry framework using a multi-institutional sample. Internet and Higher Education, 11(3-4), 133-136. Retrieved from http://dx.doi.org/10.1016/j.iheduc.2008.06.003

Garrison, D. R., \& Anderson, T. (2003). E-learning in the 21st century. London: Routledge Falmer. Retrieved from http://dx.doi.org/10.4324/9780203166093

Garrison, D. R., Anderson, T., \& Archer, W. (1991). Critical thinking and adult education: a conceptual model for developing critical thinking in adult learners. International Journal of Lifelong Education, 10(4). Retrieved from http://dx.doi.org/10.1080/0260137910100403

Garrison, D. R., Anderson, T., \& Archer, W. (2000). Critical inquiry in a text-based environment: Computer conferencing in higher education. The Internet and Higher Education, 2(2-3), 87-105. Retrieved from http://dx.doi.org/10.1016/S1096-7516(00)00016-6

Hmelo-Silver, C. E. (2003). Analyzing collaborative knowledge construction: multiple methods for integrated understanding. Computers \& Education, 41(4), 397-420. Retrieved from http://dx.doi. org/10.1016/j.compedu.2003.07.001

Järvelä, S., Näykki, P., Laru, J., \& Luokkanen., T. (2007). Structuring and regulating collaborative learning in higher education with wireless networks and mobile tools. Educational Technology \& Society, 10(4), 71-79.

Järvelä, S., Volet, S. \& Järvenoja, H. (2010). Research on motivation in collaborative learning: Moving beyond the cognitive-situative divide and combining individual and social processes. Educational Psychologist, 45(1), 15-27. Retrieved from http://dx.doi.org/10.1080/00461520903 433539

Klenner-Moore, J. (2002). Dialogic Enquiry in an Online Community. In M. Driscoll \& T. Reeves (Eds.), Proceedings of World Conference on E-Learning in Corporate, Government, Healthcare, and Higher Education 2002. Chesapeake, VA: AACE. 1714-1717. Retrieved from http://www. editlib.org/p/9340.

Monteiro, A. (2011) O currículo e a prática pedagógica com recurso ao b-learning no ensino superior. Ph.D. Thesis, Porto: Porto University.

Moore, W. (1983). Developing and Evaluating Educational Research. Boston: Little Brown and Company.

Moreira, J.A., \& Monteiro, A. (2010). O trabalho pedagógico em cenários presenciais e virtuais no ensino superior. Educação, Formação e Tecnologia, 3(2), 82-94. Retrieved from http://eft. educom.pt 
Moreira, J. A., \& Almeida, A. C. (2011). How reliable and consistent is our learning community of inquiry? Psychometric qualities of the community of inquiry survey instrument applied to a sample of higher education Portuguese students. Proceedings of the International Conference on Education and New Learning Technologies, Barcelona. 4261-4267.

Moreira, J. A. (2012). Novos cenários e modelos de aprendizagem construtivistas em plataformas digitais. In A. Monteiro, J. A. Moreira \& A. C. Almeida (Orgs.), Educação Online: Pedagogia e Aprendizagem em Plataformas Digitais (pp. 29-46), Santo Tirso: De Facto Editores.

Roschelle, J., \& Teasley, S. (1995). The construction of shared knowledge in collaborative problem solving. In C. E. O'Malley (Ed.), Computer supported collaborative learning (pp. 69-97). Heidelberg: Springer. Retrieved from http://dx.doi.org/10.1007/978-3-642-85098-1_5

Schunk, D. H., \& Zimmerman, J. (1994). Self-regulation of learning and performance. Issues and educational applications. Hillsdale, NJ: Erlbaum.

Swan, K., Shea, P., Richardson, J., Ice, P., Garrison, D. R., Cleveland-Innes, M., et al. (2008). Validating a measurement tool of presence in online communities of inquiry. E-Mentor, 2(24), 1-12 Retrieved from http://www.ementor.edu.pl/e_index.php?numer=24\&all=1

Thompson, T.L., \& Macdonald, C.J. (2005) Community building, emergent design and expecting the unexpected: Creating a quality eLearning experience. Internet and Higher Education, 8, 233-249. Retrieved from http://dx.doi.org/10.1016/j.iheduc.2005.06.004

Vaughan, N., \& Garrison, D.R. (2005). Creating cognitive presence in a blended faculty development community. The Internet and Higher Education, 8(1), 1-12. Retrieved from http://dx.doi. org/10.1016/j.ineduc.2004.11.001

White, B. \& Frederiksen, J. (1998). Inquiry, modeling, and metacognition: making science accessible to all students. Cognition and Instruction 16, 3-118. 